\title{
Competitive Balance and Revenue Sharing in Sports Leagues with Utility-Maximizing Teams
}

\author{
Helmut Dietl $^{\dagger}$, Martin Grossmann ${ }^{\dagger \dagger}$, and Markus Lang ${ }^{\dagger \dagger}$
}

October 2010

\begin{abstract}
This paper develops a contest model of a professional sports league in which clubs maximize a weighted sum of profits and wins (utility maximization). The model analyzes how more win-orientated behavior of certain clubs affects talent investments, competitive balance and club profits. Moreover, in contrast to traditional models, we show that revenue sharing does not always reduce investment incentives due to the dulling effect. We identify a new effect of revenue sharing called the "sharpening effect". In the presence of the sharpening effect (dulling effect), revenue sharing enhances (reduces) investment incentives and improves (deteriorates) competitive balance in the league.
\end{abstract}

JEL Classification Codes: L83, D43, C72

Key Words: Competitive balance, contest, invariance proposition, objective function, revenue sharing, team sports league, utility maximization

*We gratefully acknowledge the .nancial support provided by the Swiss National Science Foundation (Grants Nos. 100012-105270 and 100014-120503) and the research fund of the University of Zurich.

$\dagger$ University of Zurich, Institute for Strategy and Business Economics, Plattenstrasse 14, CH-8032 Zurich, Switzerland. Phone +41 4463453 11, Fax +41 4463453 01, helmut.dietl@isu.uzh.ch

$\dagger \dagger$ University of Zurich, Institute for Strategy and Business Economics, Plattenstrasse 14, CH-8032 Zurich, Switzerland. Phone +41 4463453 11, Fax +41 4463453 01, martin.grossmann@isu.uzh.ch

${ }^{\dagger \dagger}$ University of Zurich, Institute for Strategy and Business Economics, Plattenstrasse 14, CH-8032 Zurich, Switzerland. Phone +41 4463453 11, Fax +41 4463453 01, markus.lang@isu.uzh.ch 


\section{Introduction}

Existing models of team sports leagues assume that club owners maximize either profits (El-Hodiri and Quirk, 1971; Fort and Quirk, 1995; Szymanski and Késenne, 2004; Falconieri et al., 2004) or wins (Késenne, 2000, 2006; Zimbalist, 2003; Fort and Quirk, 2004; Vrooman, 2007). This assumption is restrictive and not supported by evidence. In contrast, empirical evidence from North American major leagues and European leagues supports the assumption that clubs trade off profits and wins (e.g., Atkinson et al., 1988; Garcia-del-Barrio and Szymanski, 2009).

Given this evidence, we present a contest model of a sports league in which club owners maximize a utility function given by a weighted sum of profits and winning percentage. As compared to previous analyses, this model is useful to develop more general propositions. In particular, the model resolves much of the controversy surrounding the famous invariance proposition (IP) of sports economics. The IP may be regarded as a predecessor of the famous Coase theorem (see Fort, 2005). According to the IP, which was introduced by Rottenberg (1956), changes in property rights, such as the introduction of a reserve clause, will not alter the allocation of playing talent within a sports league and therefore will have no impact on competitive balance. El-Hodiri and Quirk (1971), Fort and Quirk (1995) and Vrooman (1995) have extended the IP to gate revenue sharing by showing that revenue sharing has no effect on player allocation within a league. This result is of huge importance to professional team sports in general and league managers in particular because revenue sharing has been introduced as a means to increase competitive balance. The optimal level of competitive balance is crucial for overall demand and total revenues in professional sports as fans tend to prefer competitions with uncertain outcomes.

The IP with respect to revenue sharing was originally developed under the assumptions of purely profit-maximizing clubs and Walrasian conjectures. ${ }^{1}$ Késenne (2000, 2005) and Vrooman $(2007,2008)$ show that the IP does not hold in a league with purely win-maximizing clubs. Moreover, Szymanski and Késenne (2004) provide a model that contradicts the IP even under the assumption of purely profitmaximizing clubs. They show that under contest-Nash conjectures, revenue sharing

\footnotetext{
${ }^{1}$ The Walrasian conjectures $d t_{i} / d t_{j}=-1$ have been applied in the traditional literature (ElHodiri and Quirk, 1971; Fort and Quirk, 1995; Rascher, 1997) for leagues with a fixed supply of talent. These conjectures indicate that clubs internalize that due to the fixed amount of talent, a one-unit increase of talent hired at one club implies a one-unit reduction of talent at the other club. The recent literature, however, proposes the use of the contest-Nash conjectures $d t_{i} / d t_{j}=0$ to characterize non-cooperative behavior between clubs (Szymanski, 2003, 2004; Szymanski and Késenne, 2004). For a discussion regarding the Walrasian and Nash conjectures, see Szymanski (2004), Eckard (2006), and Fort and Quirk (2007).
} 
does not increase but rather decreases competitive balance: see also Dietl and Lang (2008), Vrooman (2008), and Grossmann et al. (2009). This result is driven by the so-called "dulling effect" of revenue sharing. According to the dulling effect, revenue sharing reduces the incentives for clubs to invest in playing talent because each club has to share some of the resulting marginal benefits of its talent investment with the other clubs in the league. ${ }^{2}$ Dietl et al. (2009) confirm the dulling effect of revenue sharing in a league in which one club is a pure profit maximizer and the other club is a pure win maximizer.

Our model has significant implications for competition authorities and legislators because it derives new insights regarding the effect of revenue sharing on investment incentives and competitive balance. In contrast to traditional models, our analysis shows that revenue sharing does not always reduce the incentives to invest in playing talent. We identify a new effect of revenue sharing called the "sharpening effect," which has the opposite effect of the well-known dulling effect. With our model, we can determine the conditions under which the sharpening effect or the dulling effect is at work. We show that in the presence of the sharpening effect (dulling effect), revenue sharing enhances (reduces) investment incentives and improves (deteriorates) competitive balance in the league. Moreover, we determine the conditions under which the IP holds even under contest-Nash conjectures. Finally, our model analyzes how a more win-orientated behavior of certain clubs affects talent investments, competitive balance and club profits.

Revenue-sharing schemes are widely applied in professional sports leagues all over the world. In the United States, one of the most prominent schemes is that operated by the National Football League (NFL) in which the visiting club secures $40 \%$ of the locally earned television and gate receipt revenue. In 1876, Major League Baseball (MLB) introduced a 50-50 split of gate receipts, which was reduced over time. Since 2003, all clubs in the American League have placed $34 \%$ of their locallygenerated revenue (i.e., gate revenues, concession revenues, television revenues and so on) into a central pool, which is then divided equally among all the clubs. The National Basketball Association (NBA) and the National Hockey League (NHL) also operate with a pool-sharing arrangement. In the Australian Football League (AFL), gate receipts were at one time split evenly between the home and the visiting team. This 50-50 split was finally abolished in 2000 .

The remainder of the paper is structured as follows. Section 2 presents our basic model without revenue sharing. In Section 3, we introduce a revenue-sharing arrangement and analyze its effect on talent investment and competitive balance. Finally, Section 4 concludes the paper. All proofs can be found in the Appendix.

\footnotetext{
${ }^{2}$ See also Cyrenne (2009).
} 


\section{The Basic Model}

\subsection{Notation and Assumptions}

We model a two-club league in which both clubs participate in a non-cooperative game and independently invest a certain amount $x_{i} \in \mathbb{R}^{+}$in playing talent. The difference of our model from traditional models of professional sports leagues is that, in our model, the club objective function is such that clubs maximize a utility function given by a weighted sum of profits and wins. ${ }^{3}$

The win percentage $w_{i}$ of club $i$ is characterized by the contest-success function (CSF), which maps the vector $\left(x_{1}, x_{2}\right)$ of talent investment onto probabilities for each club. We apply the logit approach, which is probably the most widely-used functional form of a CSF in sporting contests. ${ }^{4}$ The win percentage of club $i=1,2$ in this imperfectly discriminating contest is then given by

$$
w_{i}\left(x_{i}, x_{j}\right)=\frac{x_{i}}{x_{i}+x_{j}}
$$

with $i, j=1,2, i \neq j$. Given that win percentages must sum to unity, we obtain the adding-up constraint: $w_{j}=1-w_{i}$. In our model, we adopt the contestNash conjectures $\frac{d x_{i}}{d x_{j}}=0$ and compute the derivative of (1) with respect to $x_{i}$ as $\frac{\partial w_{i}}{\partial x_{i}}=\frac{x_{j}}{\left(x_{i}+x_{j}\right)^{2}}$.

The uncertainty of outcome is measured by the competitive balance in the league. One way of measuring competitive balance is through the ratio of win percentages, which is also called win ratio (Hoehn and Szymanski, 1999; Vrooman, $2007,2008)$. Without loss of generality, we define the win ratio by the ratio of club 1 's win percentage and club 2's win percentage:

$$
W R\left(x_{1}, x_{2}\right)=\frac{w_{1}\left(x_{1}, x_{2}\right)}{w_{2}\left(x_{1}, x_{2}\right)}
$$

Note that the win ratio $W R$ equals one in a fully balanced league. A win ratio that is lower or higher than one thus indicates a league with a lower degree of competitive balance.

Following the sports economic literature, we specify the revenue function of club

\footnotetext{
${ }^{3}$ One exception is Rascher (1997), who assumes that clubs maximize a linear combination of profits and wins. However, the crucial difference with respect to our model is that Rascher (1997) applies Walrasian conjectures and assumes a fixed supply of talent in the league.

${ }^{4}$ The logit CSF was generally introduced by Tullock (1980) and was subsequently axiomatized by Skaperdas (1996) and Clark and Riis (1998). Alternative functional forms include the probit CSF (Lazear and Rosen, 1981; Dixit, 1987) and the difference-form CSF (Hirshleifer, 1989). See Dietl et al. (2008) and Fort and Winfree (2009) for analyses of the CSF's discriminatory power in sporting contests.
} 
$i=1,2 \operatorname{as}^{5}$

$$
R_{i}\left(x_{i}, x_{j}\right)=m_{i} w_{i}\left(x_{i}, x_{j}\right)-\frac{b}{2} w_{i}\left(x_{i}, x_{j}\right)^{2},
$$

where $b>0$ characterizes the effect of competitive balance on club revenues and $m_{i} \in \mathbb{R}^{+}$represents the market size parameter of club $i$.

It is important to mention that club $i$ 's revenues initially increase with winning until the maximum is reached for $w_{i}^{\prime} \equiv \frac{m_{i}}{b}$. By increasing the win percentage above $w_{i}^{\prime}$, club $i$ 's revenues start to decrease because excessive dominance by one team is detrimental to club revenues. This reflects the uncertainty of outcome hypothesis; the higher $b$ is, the more important is competitive balance and the sooner revenues start to decrease due to dominance by one team.

We further assume that clubs are heterogeneous with respect to their drawing potential or market size $m_{i}$. Without loss of generality, we assume throughout this paper that club 1 is the large-market club with a high-drawing potential, while club 2 is the small-market club with a low-drawing potential such that $m_{1}>m_{2}$. As a consequence, the large-market club generates higher revenues than the small-market club for given win percentages $\left(w_{1}, w_{2}\right)$.

By assuming a competitive labor market, the market clearing cost of a unit of talent, denoted by $c$, is the same for every club. Moreover, for the sake of simplicity, we do not take into account non-labor costs and normalize the fixed capital cost to zero. ${ }^{6}$ The cost function of club $i=1,2$ is thus given by $C\left(x_{i}\right)=c x_{i}$, where $c$ is the marginal unit cost of talent.

The profit function of club $i=1,2$ is given by revenues minus costs and yields

$$
\pi_{i}\left(x_{i}, x_{j}\right)=R_{i}\left(x_{i}, x_{j}\right)-C\left(x_{i}\right)=\frac{x_{i}\left[\left(m_{i}-\frac{b}{2}\right) x_{i}+m_{i} x_{j}\right]}{\left(x_{i}+x_{j}\right)^{2}}-c x_{i},
$$

with $i, j=1,2, i \neq j$.

As mentioned above, the utility function of club $i$ is given by a weighted sum of one's own profits and wins; it is defined as:

$$
u_{i}\left(x_{i}, x_{j}\right)=\pi_{i}\left(x_{i}, x_{j}\right)+\gamma_{i} w_{i}\left(x_{i}, x_{j}\right)
$$

where $\gamma_{i} \in \mathbb{R}_{0}^{+}$is the "win preference", which characterizes the weight club owner

\footnotetext{
${ }^{5}$ This club-specific revenue function is widely used in the sports economics literature. For instance, our revenue is consistent with the revenue functions used in Hoehn and Szymanski (1999), Szymanski (2003), Szymanski and Késenne (2004), Késenne (2006, 2007) and Vrooman (2007, 2008).

${ }^{6}$ See Vrooman (1995) for a more general cost function or Késenne (2007) for a cost function with a fixed capital cost. Moreover, Grossmann et al. (2008) analyze the effect of revenue sharing on competitive balance in the case of a convex cost function with constant marginal cost elasticity.
} 
$i$ puts on winning in the utility function. A higher parameter $\gamma_{i}$ thus reflects that club owner $i$ becomes more win-orientated and less profit-orientated.

Moreover, note that we have two dimensions of heterogeneity in our model. On the one hand, clubs differ with respect to their market size and on the other hand, clubs differ regarding their win preference. In the following sections, we analyze the interaction effects of these two dimensions of heterogeneity.

\subsection{Equilibrium Analysis}

In this section, we solve the model and determine the equilibrium. Each club $i$ maximizes utility and thus solves the following maximization problem:

$$
\max _{x_{i} \geq 0}\left\{u_{i}\left(x_{i}, x_{j}\right)=\frac{x_{i}\left[\left(m_{i}-\frac{b}{2}\right) x_{i}+m_{i} x_{j}\right]}{\left(x_{i}+x_{j}\right)^{2}}-c x_{i}+\gamma_{i} \frac{x_{i}}{x_{i}+x_{j}}\right\} .
$$

The first-order conditions for club $i=1,2$ are thus given by:

$$
\frac{\partial u_{i}\left(x_{i}, x_{j}\right)}{\partial x_{i}}=\frac{x_{j}}{\left(x_{i}+x_{j}\right)^{2}}\left(m_{i}+\gamma_{i}-\frac{b x_{i}}{x_{i}+x_{j}}\right)-c=0,
$$

with $i, j=1,2$ and $i \neq j$. The solution to the above maximization problem is presented in the following lemma.

\section{Lemma 1}

In a league with utility-maximizing clubs, the equilibrium investment and win percentage of club $i$ are given by

$$
\begin{aligned}
x_{i}^{*} & =\frac{\left(\gamma_{i}+m_{i}\right)^{2}\left(\gamma_{j}+m_{j}\right)\left(m_{1}+\gamma_{1}+m_{2}+\gamma_{2}-b\right)}{c\left(m_{1}+\gamma_{1}+m_{2}+\gamma_{2}\right)^{3}}, \\
w_{i}^{*} & =\frac{m_{i}+\gamma_{i}}{m_{1}+\gamma_{1}+m_{2}+\gamma_{2}}
\end{aligned}
$$

with $i, j=1,2$ and $i \neq j$.

Proof. Straightforward and therefore omitted.

In order to guarantee positive equilibrium investments, we assume that either the clubs' market sizes or the win preferences are sufficiently large such that $m_{1}+$ $\gamma_{1}+m_{2}+\gamma_{2}>b$.

Lemma 1 shows that ceteris paribus, the win percentage of club $i$ increases with either a higher win preference $\gamma_{i}$ or a larger market size $m_{i}$ : i.e., $\frac{\partial w_{i}^{*}}{\partial \gamma_{i}}>0$ and $\frac{\partial w_{i}^{*}}{\partial m_{i}}>0$. The opposite holds true if the market size $m_{j}$ or the win preference $\gamma_{j}$ of the other club increases: i.e., $\frac{\partial w_{i}^{*}}{\partial \gamma_{j}}<0$ and $\frac{\partial w_{i}^{*}}{\partial m_{j}}<0$. 
A comparison of the equilibrium investments of the two clubs leads to the following proposition.

\section{Proposition 1}

In a league with utility-maximizing clubs, the small-market club invests more than the large-market club if and only if $m_{2}+\gamma_{2}>m_{1}+\gamma_{1}$.

Proof. Straightforward and therefore omitted.

In contrast to traditional models of sports leagues with pure profit- and/or winmaximizing clubs, in our model, it is possible that the small-market club invests more in equilibrium and, as a consequence, is the dominant team that has a higher win percentage than the large-market club. ${ }^{7}$ This outcome occurs if the utility of the small-market club has a sufficiently high win preference parameter. In this case, the win preference compensates for the lower market size such that marginal revenue is higher for the small-market club than for the large-market club, ceteris paribus. However, if the sum of market size and win preference of the large-market club is larger than (equal to) the sum of market size and win preference of the small-market club, then the former invests more than (the same as) the latter.

\subsection{The Effect on Competitive Balance}

The effect of market sizes and win preferences on competitive balance in the league is summarized in the next proposition.

\section{Proposition 2}

In a league with utility-maximizing clubs, the win ratio in equilibrium is given by

$$
W R^{*}=\frac{m_{1}+\gamma_{1}}{m_{2}+\gamma_{2}}
$$

Therefore, if clubs become more win-orientated, competitive balance may increase or decrease depending on the market size parameters $\left(m_{1}, m_{2}\right)$ and the win preference parameters $\left(\gamma_{1}, \gamma_{2}\right)$ of the two clubs.

Proof. Straightforward and therefore omitted.

As a benchmark case, consider a league with pure profit-maximizing clubs, i.e., $\gamma_{1}=\gamma_{2}=0$. In this league, the win ratio is given by $W R^{*}=m_{1} / m_{2}>1$. We know that in this case, the large-market club is the dominant team in equilibrium, while the small-market club is the underdog. If the difference in the market size of

\footnotetext{
${ }^{7}$ One exception is Grossmann and Dietl (2009), who show in a dynamic two-period contest model that an equilibrium exists in which the small club invests more than the large club in both periods.
} 
the two clubs increases (decreases), the win ratio $W R^{*}$ increases (decreases): thus, the league becomes less (more) balanced. This result is well known in the sports economics literature (Fort and Quirk, 1995; Vrooman, 1995; Szymanski, 2003).

However, if the club owner of at least one club becomes more win-orientated (i.e., $\gamma_{1}>0$ and/or $\gamma_{2}>0$ ), then the league may become more or less balanced than in the benchmark case with pure profit-maximizing clubs. To illustrate this result, consider the following three cases.

(i) The large-market club has a positive win preference and the small-market club is a pure profit-maximizer: i.e., $\gamma_{1}>0$ and $\gamma_{2}=0$. In this case, the league is less balanced than in the benchmark case, and competitive balance decreases if the large-market club becomes more win-orientated (i.e., $\gamma_{1}$ increases).

(ii) The large-market club is a pure profit-maximizer and the small-market club has a positive win preference: i.e., $\gamma_{1}=0$ and $\gamma_{2}>0$. In this case, the league is more balanced than in the benchmark case if and only if the win preference of the small-market club is sufficiently small, i.e., $\gamma_{2}<\gamma_{2}^{\prime} \equiv m_{1}^{2} / m_{2}-m_{2}$. Moreover, competitive balance increases if the small-market club becomes more win-orientated, i.e., $\gamma_{2}$ increases. If, however, $\gamma_{2}>\gamma_{2}^{\prime}$, then the league is characterized by a lower degree of competitive balance. Note that the small-market club is the dominant team, and competitive balance decreases with a higher win preference $\gamma_{2}$ of the small-market club.

(iii) Both clubs have a positive win preference: i.e., $\gamma_{1}>0$ and $\gamma_{2}>0$. As in case (ii), the league is more balanced than in the benchmark case if and only if the win preference of the small-market club is sufficiently small, i.e., $\gamma_{2}<\gamma_{2}^{\prime \prime} \equiv$ $\left[m_{1}\left(m_{1}+\gamma_{1}\right)\right] / m_{2}-m_{2}$. However, if $\gamma_{2}>\gamma_{2}^{\prime \prime}$, then the league is less balanced than in the benchmark case with the small-market club being the dominant team.

\subsection{The Effect on Club Profits}

In this section, we determine how the win preferences affect aggregate club profits in a league with utility-maximizing clubs. For this purpose, we normalize the marketsize parameters as follows: $m_{1} \equiv m$ and $m_{2} \equiv 1$, with $m>1$. Moreover, we set $b=1$. We concentrate on two cases. In case (i), the large-market club is a pure profit-maximizer, and the small-market club has a positive win preference: i.e., $\gamma_{1}=0$ and $\gamma_{2}>0$. In case (ii), the large-market club has a positive win preference, and the small-market club is a pure profit-maximizer: i.e., $\gamma_{1}>0$ and $\gamma_{2}=0 .{ }^{8}$

\footnotetext{
${ }^{8}$ Regarding the effect on utility, one can show that the utility of club $i$ increases with its win preference parameter $\gamma_{i}$ and decreases with the win preference parameter $\gamma_{j}$ of the other club. The effect on aggregate utility in the league, however, is ambiguous and depends on the parameters $\left(\gamma_{i}, m_{i}\right)$. In particular, in the case of $\gamma_{1}>0$ and $\gamma_{2}=0$, aggregate utility in the league always
} 
For case (i), we establish the following proposition.

\section{Proposition 3}

Suppose that $\gamma_{1}=0$ and $\gamma_{2}>0$. Aggregate club profits decrease when the smallmarket club becomes more win-orientated (i.e., $\gamma_{2}$ increases).

\section{Proof. See Appendix A.1.}

Consider a league in which the large-market club is a pure profit-maximizer, while the small-market club has a positive win preference: i.e., $\gamma_{1}=0$ and $\gamma_{2}>0$. If the small-market club becomes more win-orientated, then the win percentages of the small-market club increases, whereas the win percentage of the large-market club decreases (see discussion after Lemma 1). It follows that the revenues of the small-market club increase, while the revenues of the large-market club decrease through a higher win preference of the small-market club: i.e., $\partial R_{2}^{*} / \partial \gamma_{2}>0$ and $\partial R_{1}^{*} / \partial \gamma_{2}<0 .{ }^{9}$ Moreover, the small-market club increases its investment in playing talent, which induces higher costs for this club. The increase in revenues, however, cannot compensate for the increase in costs such that profits of the small-market club decrease. The large-market club, on the other hand, decreases or increases its talent investment, i.e., $\partial x_{1}^{*} / \partial \gamma_{2} \gtreqless 0 \Leftrightarrow m(m-1) \gtreqless \gamma_{2}^{2}-1$. But even if the large-market club's costs decrease due to smaller investments, club profits decrease as well because the lower costs cannot compensate for the lower revenues. Since profits of both types of clubs decrease, aggregate club profits also decrease.

For case (ii), we establish the following proposition.

\section{Proposition 4}

Suppose that $\gamma_{1}>0$ and $\gamma_{2}=0$. Aggregate club profits increase when the largemarket club becomes more win-orientated (i.e., $\gamma_{1}$ increases) if and only if the market size of the large-market club is sufficiently large.

\section{Proof. See Appendix A.2.}

Consider a league in which the large-market club has a positive win preference, while the small-market club is a pure profit-maximizer: i.e., $\gamma_{1}>0$ and $\gamma_{2}=$ 0 . In contrast to the proposition above, a higher win preference $\gamma_{1}$ yields higher revenues for the large-market club due to a higher win percentage in equilibrium. The opposite holds true for the small-market club. Moreover, talent investment and thus costs are always higher for the large-market club, whereas talent investment

increases if the large-market club becomes more win-orientated, whereas in the case of $\gamma_{1}=0$ and $\gamma_{2}>0$, the effect on aggregate utility is ambiguous if the small-market club becomes more win-orientated.

${ }^{9}$ Note that the revenue function of club $i=1,2$ is a strictly increasing function on the interval $w_{i} \in[0,1]$ for $b=1$. 
are lower for the small-market club if and only if the market size of the large-market club is sufficiently large with $m>m^{\prime} \equiv 2-\gamma_{1}$. Even though costs may decrease for the small-market club, the loss in revenues is so substantial that the profits of the small-market club always decrease.

In contrast, the profits of the large-market club increase if the market size of the large-market club is sufficiently large such that $\left(m+\gamma_{1}\right)\left[m\left(m+\gamma_{1}-2\right)-4 \gamma_{1}\right]>\gamma_{1}$ is satisfied. In this case, higher revenues compensate for higher costs. If the market size of the large-market club further increases above another threshold given by $m^{\prime \prime} \equiv 1 / 2\left(3-\gamma_{1}+\left[\left(\gamma_{1}+1\right)\left(\gamma_{1}+9\right)\right]^{1 / 2}\right)>m^{\prime}$, the higher profits of the largemarket club compensate for the lower profits of the small-market club, and aggregate club profits increase. ${ }^{10}$

\section{The Effect of Revenue Sharing in a League with Utility-Maximizing Clubs}

In this section, we integrate a gate revenue-sharing arrangement into our model and analyze its effects in a league with utility-maximizing clubs. The sharing of gate revenues plays an important role in the redistribution of revenues and has long been accepted as an exemption from antitrust law (Fort and Quirk, 1995; Szymanski, 2003). The basic idea of this cross-subsidization policy is to redistribute revenues from large-market clubs to small-market clubs because large-market clubs have a higher revenue-generating potential than do small-market clubs.

In its simplest form, gate revenue sharing allows the visiting club to retain a share of the home club's gate revenues. The after-sharing revenues of club $i$ are given by $\widehat{R}_{i}=\alpha R_{i}+(1-\alpha) R_{j}$, with $i, j=1,2$ and $i \neq j$. Note that the share of revenues that is assigned to the home team is given by the parameter $\alpha \in[1 / 2,1]$, while $(1-\alpha)$ is assumed to be the share of revenues received by the away team.

Thus, the utility of club $i$ in a league with utility-maximizing clubs is given by $\widehat{u}_{i}=\widehat{R}_{i}-c x_{i}+\gamma_{i} w_{i}$. Maximizing utility $\widehat{u}_{i}$ yields the following maximization problem of club $i=1,2$ :

$\max _{x_{i} \geq 0}\left\{\alpha \frac{x_{i}\left[\left(m_{i}-\frac{b}{2}\right) x_{i}+m_{i} x_{j}\right]}{\left(x_{i}+x_{j}\right)^{2}}+(1-\alpha) \frac{x_{j}\left[\left(m_{j}-\frac{b}{2}\right) x_{j}+m_{j} x_{i}\right]}{\left(x_{i}+x_{j}\right)^{2}}-c x_{i}+\gamma_{i} \frac{x_{i}}{x_{i}+x_{j}}\right\}$,

with $i, j=1,2, i \neq j$.

\footnotetext{
${ }^{10}$ In a league in which both clubs have a positive win preference (i.e., $\gamma_{1}>0$ and $\gamma_{2}>0$ ) a higher win preference $\gamma_{2}$ for the small-market club always yields lower profits for both clubs. The effect of a higher win preference $\gamma_{1}$ for the large-market club on club profits, however, is ambiguous.
} 
The corresponding first-order conditions are computed as

$$
\frac{\partial \widehat{u}_{i}\left(x_{1}, x_{2}\right)}{\partial x_{i}}=\left(\alpha \frac{\partial R_{i}}{\partial w_{i}}-(1-\alpha) \frac{\partial R_{j}}{\partial w_{j}}+\gamma_{i}\right) \frac{\partial w_{i}}{\partial x_{i}}-c=0
$$

with $\frac{\partial w_{j}}{\partial x_{i}}=-\frac{\partial w_{i}}{\partial x_{i}}$. Rearranging the first-order conditions yields

$$
\begin{aligned}
& \frac{\partial \widehat{u}_{1}\left(x_{1}, x_{2}\right)}{\partial x_{1}}=\left(\gamma_{1}+\alpha\left(m_{1}-b\right)-(1-\alpha) m_{2}+\frac{b x_{2}}{x_{1}+x_{2}}\right) \frac{x_{2}}{\left(x_{1}+x_{2}\right)^{2}}-c=0, \\
& \frac{\partial \widehat{u}_{2}\left(x_{1}, x_{2}\right)}{\partial x_{2}}=\left(\gamma_{2}+\alpha\left(m_{2}-b\right)-(1-\alpha) m_{1}+\frac{b x_{1}}{x_{1}+x_{2}}\right) \frac{x_{1}}{\left(x_{1}+x_{2}\right)^{2}}-c=0,
\end{aligned}
$$

We determine the equilibrium win percentages in the following lemma.

\section{Lemma 2}

In a league with utility-maximizing clubs and a revenue-sharing arrangement, the equilibrium win percentage of club $i$ is given by

$$
\widehat{w}_{i}^{*}=\frac{\gamma_{i}+\alpha\left(m_{i}-b\right)-(1-\alpha) m_{j}+b}{\left(m_{1}+m_{2}\right)(2 \alpha-1)+2 b(1-\alpha)+\gamma_{1}+\gamma_{2}},
$$

with $i, j=1,2, i \neq j$.

\section{Proof. See Appendix A.3.}

From Lemma 2, we compute the equilibrium win ratio in a league with utilitymaximizing clubs as:

$$
\widehat{W R}^{*}=\frac{\widehat{w}_{1}^{*}}{\widehat{w}_{2}^{*}}=\frac{\gamma_{1}+\alpha\left(m_{1}-b\right)-(1-\alpha) m_{2}+b}{\gamma_{2}+\alpha\left(m_{2}-b\right)-(1-\alpha) m_{1}+b} \gtreqless 1 .
$$

As in a league without revenue sharing, the small-market club invests more in equilibrium and consequently has a higher win percentage than the large-market club if and only if the sum of the market size and win preference for the small-market club is larger than that for the large-market club: i.e., $m_{2}+\gamma_{2}>m_{1}+\gamma_{1} \cdot{ }^{11}$ In this case, we obtain $\widehat{W R}^{*}<1$. If, however, $m_{2}+\gamma_{2} \leq m_{1}+\gamma_{1}$, then the large-market club does not invest less than the small-market club, i.e., $\widehat{W R}^{*} \geq 1$.

Regarding the effect of revenue sharing on club revenues, we compute the partial derivative of club $i$ 's marginal revenue $M R_{i}=\partial \widehat{R}_{i} / \partial w_{i}$ with respect to the revenuesharing parameter $\alpha$ as:

$$
\frac{\partial M R_{i}}{\partial \alpha}=\frac{x_{j}}{\left(x_{1}+x_{2}\right)^{2}}\left(m_{1}+m_{2}-b\right) \gtreqless 0,
$$

\footnotetext{
${ }^{11}$ Note that this condition does not depend on the revenue-sharing parameter $\alpha$.
} 
with $i, j=1,2, i \neq j$. We derive that a higher degree of revenue sharing (i.e., a lower parameter $\alpha$ ) has a positive effect on club $i$ 's marginal revenue if $b>m_{1}+m_{2}$, while it has a negative effect on marginal revenue if $b<m_{1}+m_{2}$. In the case that $b=m_{1}+m_{2}$, revenue sharing has no effect on marginal revenue.

To further analyze the effect of revenue sharing on competitive balance, we derive the partial derivative of the win ratio $\widehat{W R}^{*}$ as:

$$
\frac{\partial \widehat{W R}^{*}}{\partial \alpha}=\frac{\left[b-\left(m_{1}+m_{2}\right)\right]\left[\left(m_{1}+\gamma_{1}\right)-\left(m_{2}+\gamma_{2}\right)\right]}{\left(\gamma_{2}+\alpha\left(m_{2}-b\right)-(1-\alpha) m_{1}+b\right)^{2}} \gtreqless 0 .
$$

In equilibrium, the effect of revenue sharing on the win ratio and the incentives to invest depends on how revenue sharing affects marginal revenue (i.e., $b \gtreqless m_{1}+m_{2}$ ) as well as on which club is the dominant team in equilibrium (i.e., $m_{1}+\gamma_{1} \gtreqless m_{2}+\gamma_{2}$ ).

We proceed by differentiating three cases. ${ }^{12}$ In Section 3.1, revenue sharing has a positive effect on marginal revenue: i.e., $b>m_{1}+m_{2}$. In Section 3.2, revenue sharing has a negative effect on marginal revenue: i.e., $b<m_{1}+m_{2}$. Finally, in Section 3.3, revenue sharing has no effect on marginal revenue: i.e., $b=m_{1}+m_{2}$.

\subsection{The Sharpening Effect of Revenue Sharing}

The integration of a win preference parameter $\gamma_{i}$ for club $i$ allows that the case in which revenue sharing has a positive effect on marginal revenue is a feasible equilibrium outcome. Without a win preference parameter, the parameter constellation $b>m_{1}+m_{2}$ would not constitute an equilibrium. This parameterization implies that in equilibrium, the win percentage $\widehat{w}_{1}^{*}$ of the large-market club and/or the win percentage $\widehat{w}_{2}^{*}$ of the small-market club are higher than the revenue-maximizing win percentages $w_{1}^{\prime}=m_{1} / b$ and/or $w_{2}^{\prime}=m_{2} / b$. In this case, the marginal revenue of club 1 and/or club 2 would be negative, which is not feasible in equilibrium. The negative marginal revenue, however, can be compensated by additional marginal revenue through the integration of a win preference parameter $\gamma_{i}$. Due to this additional effect with respect to the marginal revenue of investment, the parameter constellation $b>m_{1}+m_{2}$ is feasible in equilibrium.

In the case that revenue sharing has a positive effect on marginal revenue, we establish the following proposition.

\section{Proposition 5}

Suppose that $b>m_{1}+m_{2}$. In a league with utility-maximizing clubs, a higher degree of revenue sharing will:

\footnotetext{
${ }^{12}$ Note that we only have to consider marginal revenue in order to generate insights regarding the equilibrium conditions, as marginal costs are constant and independent of revenue sharing.
} 
(a) increase the amount of talent hired by each club, and

(b) increase competitive balance if either the small-market club or the largemarket club is the dominant team in equilibrium. In the case that both clubs have equal playing strength in equilibrium, the IP holds.

\section{Proof. See Appendix A.4.}

With respect to part (a) and in contrast to the established literature, ${ }^{13}$ this proposition shows that revenue sharing does not necessarily reduce incentives to invest in playing talent. If revenue sharing has a positive effect on marginal revenue for both clubs, then a higher degree of revenue sharing enhances incentives to invest in playing talent, and both clubs will increase the amount of talent hired in equilibrium. Thus, we identify a new effect of revenue sharing that we call the "sharpening effect." Note that this sharpening effect of revenue sharing has the opposite effect of the dulling effect described in Section 3.2. ${ }^{14}$

Furthermore, part (b) shows that in the presence of the sharpening effect, a revenue-sharing arrangement proves to be an efficient instrument for improving competitive balance in an unbalanced league. We explain the intuition behind this result as follows.

If the large-market club is the dominant team in equilibrium (i.e., $\widehat{W R}^{*}>1$ ), ${ }^{15}$ then the positive effect of revenue sharing on marginal revenue is stronger for the underdog (i.e., small-market club) than for the dominant team (i.e., large-market club) due to the logit formulation of the CSF. As a consequence, the sharpening effect of revenue sharing is more pronounced for the underdog than for the dominant team, since the (negative) marginal impact on the dominant team's revenues of an increase in talent investment by the underdog is greater than the (negative) marginal impact on the underdog's revenues of an increase in talent investment by the dominant team. As a consequence, the small-market club will increase its investment level relatively more than the large-market club such that the league becomes more balanced through revenue sharing.

If, however, the small-market club is the dominant team in equilibrium (i.e., $\left.\widehat{W R}^{*}<1 \Leftrightarrow m_{1}+\gamma_{1}<m_{2}+\gamma_{2}\right)$, then the positive effect of revenue sharing on marginal revenue is stronger for the large-market club than for the small-market club. In this case, the sharpening effect of revenue sharing is stronger for the largemarket club. Again, the underdog (in this case, the large-market club) will increase its investment level relatively more than the dominant team (in this case, the small-

\footnotetext{
${ }^{13}$ See Szymanski (2003), Szymanski and Késenne (2004), Cyrenne (2009) and Dietl et al. (2009).

${ }^{14}$ The dulling effect describes the well-known result in sports economics that revenue sharing reduces the incentive to invest in playing talent (see Szymanski and Késenne, 2004).

${ }^{15}$ Remember that $\widehat{W R}^{*}>1$ holds if and only if $m_{1}+\gamma_{1}>m_{2}+\gamma_{2}$.
} 
market club) such that the league becomes more balanced through revenue sharing.

In the case that the league is already perfectly balanced (i.e., both clubs have equal playing strength in equilibrium such that $\widehat{W R}^{*}=1$ ), the (marginal) sharpening effect of revenue sharing is equally strong for both clubs. As a consequence, both clubs will marginally increase their investment level at an equal rate and competitive balance will not be altered through revenue sharing such that the IP holds.

\subsection{The Dulling Effect of Revenue Sharing}

In the case that revenue sharing has a negative effect on marginal revenue, we establish the following proposition:

\section{Proposition 6}

Suppose that $b<m_{1}+m_{2}$. In a league with utility-maximizing clubs, a higher degree of revenue sharing will:

(a) reduce the amount of talent hired by each club, and

(b) decrease competitive balance if either the small-market club or the largemarket club is the dominant team in equilibrium. In the case that both clubs have equal playing strength in equilibrium, the IP holds.

\section{Proof. See Appendix A.5.}

Part (a) shows that each club reduces the amount of talent hired in equilibrium if revenue sharing has a negative effect on marginal revenue of both clubs in equilibrium. That is, in this case, the well-known dulling effect of revenue sharing is present.

Part (b) shows that a revenue-sharing arrangement will worsen the competitive balance in an already unbalanced league if revenue sharing has a negative effect on marginal revenue. With a similar argumentation as above, this dulling effect is more pronounced for the underdog than for the dominant team, since the (positive) marginal impact on the dominant team's revenues of a decrease in talent investment by the underdog is greater than the (positive) marginal impact on the underdog's revenues of a decrease in talent investment by the dominant team. If the largemarket club is the dominant team in equilibrium, then the small-market club will reduce its investment level relatively more than the large-market club such that the league becomes less balanced through revenue sharing. This replicates the result of Szymanski and Késenne (2004).

If, however, the small-market club is the dominant team in equilibrium, then the dulling effect of revenue sharing is stronger for the large-market club than for the small-market club. In this case, the large-market club will reduce its investment 
level relatively more than the small-market club. As a result, the league becomes again less balanced through revenue sharing.

In the case that the league is already perfectly balanced, the (marginal) dulling effect is equally strong for both clubs such that both clubs will marginally decrease their investment level at an equal rate. As a consequence, competitive balance will not be altered through revenue sharing, and the IP holds again.

\subsection{No Effect of Revenue Sharing}

In the case that revenue sharing has no effect on marginal revenue, we establish the following proposition.

\section{Proposition 7}

Suppose that $b=m_{1}+m_{2}$. In a league with utility-maximizing clubs, a higher degree of revenue sharing has no effect on equilibrium investment such that the IP holds.

Proof. See proof of Proposition 5.

The proposition shows that revenue sharing has no effect on talent investment, and thus, it does not change the level of competitive balance in the league if revenue sharing has no effect on marginal revenue. As a consequence, the IP with respect to revenue sharing holds even under contest-Nash conjectures. Note that up until now, the IP has been derived only under Walrasian conjectures.

\section{Conclusion}

In this paper, we develop a contest model of a sports league and introduce a more general objective function for club owners by assuming that clubs maximize a weighted sum of profits and wins. This approach fundamentally differs from traditional analyses of sports leagues, which assume either pure profit-maximizing and/or win-maximizing clubs. Evidence from the real world of major sports leagues, however, suggests that clubs trade off profits and wins.

Our model has significant implications for competition authorities and legislators because it provides new insights regarding the effect of revenue sharing on investment incentives as well as determines the conditions under which revenue sharing increases or decreases competitive balance. The model also analyzes how more win-orientated behavior of certain clubs affects talent investment, competitive balance and club profits. In particular, we show that the small-market club will be the dominant team in equilibrium and will invest more than the large-market club if the small-market club has a sufficiently high preference for winning. In this case, 
the resulting incentive effect to invest in playing talent compensates for the size effect. The effect of more win-orientated behavior of certain clubs on the competitive balance in the league is ambiguous and depends on the market-size parameters and the win preferences. We further show that aggregate club profits decrease with a more win-orientated behavior on the part of the small-market club in a league in which the large-market club is a pure profit-maximizer. On the other hand, in a league in which the small-market club is a pure profit-maximizer, aggregate club profits may increase through a more win-orientated behavior on the part of the large-market club.

Regarding the effect of revenue sharing, our analysis shows that contrary to traditional models, revenue sharing may enhance incentives to invest in playing talent. Thus, we identify a new effect of revenue sharing called the "sharpening effect", which has the opposite effect of the well-known dulling effect. As a consequence, revenue sharing may increase or decrease competitive balance, or it may have no effect on competitive balance such that the invariance proposition (IP) holds. The effect of revenue sharing on competitive balance depends on (i) which club has a higher win percentage and thus is the dominant team in equilibrium, and (ii) whether the sharpening or dulling effect of revenue sharing is at work. The following table summarizes the results.

Table 1: Effect of Revenue Sharing on Competitive Balance

\begin{tabular}{|l|c|c|c|}
\hline & $\begin{array}{c}\text { Large-market club } \\
\text { is dominant team }\end{array}$ & $\begin{array}{c}\text { Fully balanced } \\
\text { competition }\end{array}$ & $\begin{array}{c}\text { Small-market club } \\
\text { is dominant team }\end{array}$ \\
\hline$b>m_{1}+m_{2}$ & CB increases & IP holds & CB increases \\
\hline$b<m_{1}+m_{2}$ & CB decreases & IP holds & CB decreases \\
\hline$b=m_{1}+m_{2}$ & IP holds & IP holds & IP holds \\
\hline
\end{tabular}

Remember that the sharpening effect is present if revenue sharing has a positive effect on marginal revenue (i.e., $b>m_{1}+m_{2}$ ), whereas the dulling effect is present if revenue sharing has a negative effect on marginal revenue (i.e., $b<m_{1}+m_{2}$ ). If $b=m_{1}+m_{2}$, then revenue sharing has no effect on marginal revenue. Also recall that in equilibrium the sharpening or dulling effect is always more pronounced for the underdog than for the dominant team. ${ }^{16}$ As a consequence, the effect of revenue sharing on competitive balance crucially depends on whether the sharpening effect or the dulling effect is at work.

\footnotetext{
${ }^{16}$ Note that the large-market club is the dominant team in equilibrium if $m_{1}+\gamma_{1}>m_{2}+\gamma_{2}$, whereas the small-market club is the dominant team in equilibrium if $m_{1}+\gamma_{1}<m_{2}+\gamma_{2}$. The league is perfectly balanced if $m_{1}+\gamma_{1}=m_{2}+\gamma_{2}$.
} 
Table 1 shows that, in the presence of the sharpening effect (dulling effect), revenue sharing will improve (deteriorate) competitive balance if the league is not yet fully balanced. This holds true independent of which club is the dominant team in equilibrium. In the case in which the league is already fully balanced in equilibrium (i.e., both clubs have the same win percentage), then revenue sharing has no effect on competitive balance, and the IP holds. The IP also holds if revenue sharing has no effect on marginal revenue, independent of whether the league is already fully balanced.

An interesting avenue for further research in this area is the analysis of salary restrictions (caps and floors). A salary cap (floor) puts an upper (lower) bound on a club's payroll and have been introduced as a measure to improve competitive balance in sports leagues. Salary restrictions are widely applied in professional sports leagues all over the world. In the NHL, for example, each team had to spend between US $\$ 34.3$ million and 50.3 million on player salaries in the 2007-08 season. In the NFL, the salary cap in 2009 is approximately US\$128 million per team, whereas the salary floor was $87.6 \%$ of the salary cap, which is equivalent to US\$ 112.1 million. The AFL also operates with a combined salary cap and floor: for 2009 , the salary cap was fixed at $\mathrm{A} \$ 7.69$ million, the floor at 7.12 million. ${ }^{17}$ Our model framework can be used to analyze the effect of such salary restrictions on competitive balance, talent investment, and club profits in sports leagues with utility-maximizing clubs.

\footnotetext{
${ }^{17}$ The data is taken from the collective bargaining agreements of the respective leagues.
} 


\section{A Appendix}

\section{A.1 Proof of Proposition 3}

Suppose that $m_{1}=m$ and $m_{2}=1$ with $m>1$ and $b=1$. Moreover, consider a league in which the large-market club is a pure profit-maximizer and the smallmarket club has a positive win preference, i.e., $\gamma_{1}=0$ and $\gamma_{2}>0$. In this scenario, equilibrium talent investments are given by

$$
\left(x_{1}^{*}, x_{2}^{*}\right)=\left(\frac{m^{2}\left(m+\gamma_{2}\right)\left(1+\gamma_{2}\right)}{c\left(1+m+\gamma_{2}\right)^{3}}, \frac{m\left(m+\gamma_{2}\right)\left(1+\gamma_{2}\right)^{2}}{c\left(1+m+\gamma_{2}\right)^{3}}\right) .
$$

The partial derivatives of talent investments with respect to the win preference parameter $\gamma_{2}$ yield

$$
\begin{aligned}
\frac{\partial x_{1}^{*}}{\partial \gamma_{2}} & =\frac{m^{2}\left(1+m(m-1)-\gamma_{2}^{2}\right)}{c\left(1+\gamma_{2}+m\right)^{4}}>0 \Leftrightarrow 1+m^{2}>\gamma_{2}^{2}+m, \\
\frac{\partial x_{2}^{*}}{\partial \gamma_{2}} & =\frac{\left(1+\gamma_{2}\right) m\left(1+\gamma_{2}+2 \gamma_{2} m+2 m^{2}\right)}{c\left(1+\gamma_{2}+m\right)^{4}}>0,
\end{aligned}
$$

for all $c>0, m>1$ and $\gamma_{2}>0$.

The profit of club $i=1,2$ is given by

$$
\begin{aligned}
\pi_{1}^{*} & =\frac{m^{2}\left(1+m(2 m+1)+\gamma_{2}(2 m+1)\right)}{2\left(m+\gamma_{2}+1\right)^{3}} \\
\pi_{2}^{*} & =\frac{\left(1+\gamma_{2}\right)\left(m\left(3+\gamma_{2}-2 \gamma_{2}^{2}\right)+\left(1+\gamma_{2}\right)^{2}-2 m^{2} \gamma_{2}\right)}{2\left(m+\gamma_{2}+1\right)^{3}}
\end{aligned}
$$

The partial derivatives of club profits with respect to the win preference parameter $\gamma_{2}$ yield:

$$
\begin{aligned}
& \frac{\partial \pi_{1}^{*}}{\partial \gamma_{2}}=-\frac{m^{2}\left(1+2 m\left(m+\gamma_{2}\right)+\gamma_{2}\right)}{\left(m+\gamma_{2}+1\right)^{4}}<0 \\
& \frac{\partial \pi_{2}^{*}}{\partial \gamma_{2}}=-\frac{m\left(\left(1+\gamma_{2}\right)^{2}+m^{2}\left(1+2 \gamma_{2}\right)+m\left(\gamma_{2}\left(2 \gamma_{2}+1\right)-1\right)\right.}{\left(m+\gamma_{2}+1\right)^{4}}<0
\end{aligned}
$$

for all $c>0, m>1$ and $\gamma_{2}>0$. This means that profits of the small-market club and the large-market club always decrease with a higher win preference $\gamma_{2}$. It follows that aggregate club profits also decrease. This completes the proof of the proposition. 


\section{A.2 Proof of Proposition 4}

Suppose that $m_{1}=m$ and $m_{2}=1$ with $m>1$ and $b=1$. Moreover, consider a league in which the large-market club has a positive win preference and the smallmarket club is a pure profit-maximizer, i.e., $\gamma_{1}>0$ and $\gamma_{2}=0$. In this scenario, equilibrium talent investments are given by

$$
\left(x_{1}^{*}, x_{2}^{*}\right)=\left(\frac{\left(m+\gamma_{1}\right)^{3}}{c\left(1+m+\gamma_{1}\right)^{3}}, \frac{\left(m+\gamma_{1}\right)^{2}}{c\left(1+m+\gamma_{1}\right)^{3}}\right) \text {. }
$$

The partial derivatives of talent investments with respect to the win preference parameter $\gamma_{1}$ yield

$$
\begin{aligned}
\frac{\partial x_{1}^{*}}{\partial \gamma_{1}} & =\frac{3\left(\gamma_{1}+m\right)^{2}}{c\left(1+\gamma_{1}+m\right)^{4}}>0 \\
\frac{\partial x_{2}^{*}}{\partial \gamma_{1}} & =\frac{\left(2-\gamma_{1}-m\right)\left(\gamma_{1}+m\right)}{c\left(1+\gamma_{1}+m\right)^{4}}>0 \Leftrightarrow m<2-\gamma_{1}
\end{aligned}
$$

The profit of club $i=1,2$ is given by

$$
\begin{aligned}
\pi_{1}^{*} & =\frac{\left(m+\gamma_{1}\right)\left[\left(m+\gamma_{1}\right)\left(1-m-\gamma_{1}\right)+2\left(1+m+\gamma_{1}\right)\left(m^{2}+\gamma_{1}(m-1)\right]\right.}{2\left(m+\gamma_{1}+1\right)^{3}}, \\
\pi_{2}^{*} & =\frac{1+3\left(m+\gamma_{1}\right)}{2\left(m+\gamma_{1}+1\right)^{3}} .
\end{aligned}
$$

The partial derivative of club 1's profits with respect to the win preference parameter $\gamma_{1}$ yields:

$\frac{\partial \pi_{1}^{*}}{\partial \gamma_{1}}=\frac{\left(m+\gamma_{1}\right)\left[m\left(m+\gamma_{1}-2\right)-4 \gamma_{1}\right]-\gamma_{1}}{\left(m+\gamma_{1}+1\right)^{4}}>0 \Leftrightarrow\left(m+\gamma_{1}\right)\left[m\left(m+\gamma_{1}-2\right)-4 \gamma_{1}\right]>\gamma_{1}$.

The inequality is satisfied for $m$ sufficiently large.

The partial derivative of club 2's profits with respect to the win preference parameter $\gamma_{1}$ yields:

$$
\frac{\partial \pi_{2}^{*}}{\partial \gamma_{1}}=-\frac{3\left(m+\gamma_{1}\right)}{\left(m+\gamma_{1}+1\right)^{4}}<0
$$

for all $c>0, m>1$ and $\gamma_{2}>0$.

The partial derivative of aggregate club profits with respect to the win preference parameter $\gamma_{1}$ is given by

$$
\frac{\partial\left(\pi_{1}^{*}+\pi_{2}^{*}\right)}{\partial \gamma_{2}}=\frac{m\left(m+\gamma_{1}-3\right)-4 \gamma_{1}}{\left(m+\gamma_{1}+1\right)^{3}}>0 \Leftrightarrow m\left(m+\gamma_{1}-3\right)>4 \gamma_{1}
$$

The last inequality is satisfied for $m>m^{\prime \prime} \equiv 1 / 2\left(3-\gamma_{1}+\left[\left(\gamma_{1}+1\right)\left(\gamma_{1}+9\right)\right]^{1 / 2}\right)$. 
This completes the proof of the proposition.

\section{A.3 Proof of Lemma 2}

Rewriting the first-order conditions, we obtain:

$$
\begin{aligned}
& \frac{\partial \hat{u}_{1}\left(x_{1}, x_{2}\right)}{\partial x_{1}}=\frac{x_{2}}{\left(x_{1}+x_{2}\right)^{3}}\left[\left(x_{1}+x_{2}\right)(\underbrace{\gamma_{1}-m_{2}(1-\alpha)+\alpha m_{1}-b \alpha}_{\equiv r})+b x_{2}\right]-c=0 \\
& \frac{\partial \hat{u}_{2}\left(x_{1}, x_{2}\right)}{\partial x_{2}}=\frac{x_{1}}{\left(x_{1}+x_{2}\right)^{3}}\left[\left(x_{1}+x_{2}\right)(\underbrace{\gamma_{2}-m_{1}(1-\alpha)+\alpha m_{2}-b \alpha}_{\equiv s})+b x_{1}\right]-c=0
\end{aligned}
$$

Combining both equations and rearranging yields

$$
\left(x_{1}+x_{2}\right)\left(x_{2} r-x_{1} s+b x_{2}-b x_{1}\right)=0
$$

In equilibrium $\left(x_{1}^{*}, x_{2}^{*}\right)$, it must hold:

$$
x_{1}^{*}=\frac{r+b}{s+b} x_{2}^{*}=\frac{\gamma_{1}-m_{2}(1-\alpha)+\alpha\left(m_{1}-b\right)+b}{\gamma_{2}-m_{1}(1-\alpha)+\alpha\left(m_{2}-b\right)+b} x_{2}^{*}
$$

This implies that

$$
\widehat{w}_{i}^{*}=\frac{x_{i}^{*}}{x_{1}^{*}+x_{2}^{*}}=\frac{\gamma_{i}+\alpha\left(m_{i}-b\right)-(1-\alpha) m_{j}+b}{\left(m_{1}+m_{2}\right)(2 \alpha-1)+2 b(1-\alpha)+\gamma_{1}+\gamma_{2}}
$$

with $i, j=1,2$ and $i \neq j$. This completes the proof of the lemma.

\section{A.4 Proof of Proposition 5}

Part (a) We claim that the effect of more revenue sharing on talent investments depends on how revenue sharing affects marginal revenue in equilibrium. In this proof, we will show that a higher degree of revenue sharing (i) decreases equilibrium investment of each club if $b<m_{1}+m_{2}$, (ii) increases equilibrium investment of each club if $b>m_{1}+m_{2}$, and (iii) has no effect on equilibrium investment of each club if $b=\left(m_{1}+m_{2}\right)$.

To prove this claim, we derive the total differential of the first-order conditions $\frac{\partial \widehat{u}_{1}}{\partial x_{1}}=0$ and $\frac{\partial \widehat{u}_{1}}{\partial x_{2}}=0$ :

$$
\begin{aligned}
& \frac{\partial^{2} \widehat{u}_{1}}{\partial x_{1}^{2}} d x_{1}+\frac{\partial^{2} \widehat{u}_{1}}{\partial x_{1} \partial x_{2}} d x_{2}+\frac{\partial^{2} \widehat{u}_{1}}{\partial x_{1} \partial \alpha} d \alpha=0 \\
& \frac{\partial^{2} \widehat{u}_{2}}{\partial x_{2} \partial x_{1}} d x_{1}+\frac{\partial^{2} \widehat{u}_{2}}{\partial x_{2}^{2}} d x_{2}+\frac{\partial^{2} \widehat{u}_{2}}{\partial x_{2} \partial \alpha} d \alpha=0
\end{aligned}
$$


For notational convenience, we write: $\frac{\partial^{2} \widehat{u}_{1}}{\partial x_{1}^{2}}=\widehat{u}_{11}, \frac{\partial^{2} \widehat{u}_{1}}{\partial x_{2} \partial x_{1}}=\widehat{u}_{12}, \frac{\partial^{2} \widehat{u}_{1}}{\partial \alpha \partial x_{1}}=\widehat{u}_{1 \alpha}$ and $\frac{\partial^{2} \widehat{u}_{2}}{\partial x_{2}^{2}}=\widehat{u}_{22}, \frac{\partial^{2} \widehat{u}_{2}}{\partial x_{1} \partial x_{2}}=\widehat{u}_{21}, \frac{\partial^{2} \widehat{u}_{2}}{\partial \alpha \partial x_{2}}=\widehat{u}_{2 \alpha}$. Moreover, $R_{i}^{\prime}=\frac{\partial R_{i}}{\partial w_{i}}$ and $R_{i}^{\prime \prime}=\frac{\partial^{2} R_{i}}{\partial w_{i}}$ for $i=1,2$.

The total differential of the first-order conditions from above can also be written as

$$
\left[\begin{array}{ll}
\widehat{u}_{11} & \widehat{u}_{12} \\
\widehat{u}_{21} & \widehat{u}_{22}
\end{array}\right]\left[\begin{array}{l}
d x_{1} \\
d x_{2}
\end{array}\right]=\left[\begin{array}{c}
-\widehat{u}_{1 \alpha} \\
-\widehat{u}_{2 \alpha}
\end{array}\right] d \alpha,
$$

where

$$
\begin{aligned}
& \widehat{u}_{11}=\left(\alpha R_{1}^{\prime}-(1-\alpha) R_{2}^{\prime}+\gamma_{1}\right)\left(\frac{-2 w_{2}}{\left(x_{1}+x_{2}\right)^{2}}\right)+\left(\alpha R_{1}^{\prime \prime}+(1-\alpha) R_{2}^{\prime \prime}\right)\left(\frac{w_{2}^{2}}{\left(x_{1}+x_{2}\right)^{2}}\right), \\
& \widehat{u}_{12}=\left(\alpha R_{1}^{\prime}-(1-\alpha) R_{2}^{\prime}+\gamma_{1}\right)\left(\frac{w_{1}-w_{2}}{\left(x_{1}+x_{2}\right)^{2}}\right)-\left(\alpha R_{1}^{\prime \prime}+(1-\alpha) R_{2}^{\prime \prime}\right)\left(\frac{w_{1} w_{2}}{\left(x_{1}+x_{2}\right)^{2}}\right), \\
& \widehat{u}_{21}=\left(\alpha R_{2}^{\prime}-(1-\alpha) R_{1}^{\prime}+\gamma_{2}\right)\left(\frac{w_{2}-w_{1}}{\left(x_{1}+x_{2}\right)^{2}}\right)-\left(\alpha R_{2}^{\prime \prime}+(1-\alpha) R_{1}^{\prime \prime}\right)\left(\frac{w_{1} w_{2}}{\left(x_{1}+x_{2}\right)^{2}}\right), \\
& \widehat{u}_{22}=\left(\alpha R_{2}^{\prime}-(1-\alpha) R_{1}^{\prime}+\gamma_{2}\right)\left(\frac{-2 w_{1}}{\left(x_{1}+x_{2}\right)^{2}}\right)+\left(\alpha R_{2}^{\prime \prime}+(1-\alpha) R_{1}^{\prime \prime}\right)\left(\frac{w_{1}^{2}}{\left(x_{1}+x_{2}\right)^{2}}\right), \\
& \widehat{u}_{1 \alpha}=\left(R_{1}^{\prime}+R_{2}^{\prime}\right) \frac{w_{2}}{x_{1}+x_{2}}=\left(m_{1}+m_{2}-b\right) \frac{w_{2}}{x_{1}+x_{2}}, \\
& \widehat{u}_{2 \alpha}=\left(R_{1}^{\prime}+R_{2}^{\prime}\right) \frac{w_{1}}{x_{1}+x_{2}}=\left(m_{1}+m_{2}-b\right) \frac{w_{1}}{x_{1}+x_{2}} .
\end{aligned}
$$

Note that in equilibrium it must hold that

$\alpha R_{1}^{\prime}-(1-\alpha) R_{2}^{\prime}+\gamma_{1}=\frac{c\left(x_{1}+x_{2}\right)}{w_{2}}>0$ and $\alpha R_{2}^{\prime}-(1-\alpha) R_{1}^{\prime}+\gamma_{2}=\frac{c\left(x_{1}+x_{2}\right)}{w_{1}}>0$

Applying Cramer's Rule to (15), we derive

$$
\frac{d x_{1}}{d \alpha}=\frac{\widehat{u}_{12} \widehat{u}_{2 \alpha}-\widehat{u}_{22} \widehat{u}_{1 \alpha}}{\widehat{u}_{11} \widehat{u}_{22}-\widehat{u}_{12} \widehat{u}_{21}} \text { and } \frac{d x_{2}}{d \alpha}=\frac{\widehat{u}_{21} \widehat{u}_{1 \alpha}-\widehat{u}_{11} \widehat{u}_{2 \alpha}}{\widehat{u}_{11} \widehat{u}_{22}-\widehat{u}_{12} \widehat{u}_{21}}
$$

In order to ensure a maximum, we need the stability condition $\widehat{u}_{11} \widehat{u}_{22}-\widehat{u}_{12} \widehat{u}_{21}>0$. Therefore, the denominator has to be positive (see, e.g., Dixit, 1986 and Szymanski and Késenne, 2004).

The sign of the numerator depends on how revenue sharing affects marginal revenue. We differentiate three cases:

(i) Assume that $b<m_{1}+m_{2}$. In this case, $\widehat{u}_{1 \alpha}>0$ and $\widehat{u}_{2 \alpha}>0$.

(ia) If club 1 is the dominant team in equilibrium, i.e., $w_{1}>w_{2}$, then $\widehat{u}_{12}>0$ and thus the numerator $\widehat{u}_{12} \widehat{u}_{2 \alpha}-\widehat{u}_{22} \widehat{u}_{1 \alpha}$ of $\frac{d x_{1}}{d \alpha}$ is positive. It follows that $\frac{d x_{1}}{d \alpha}>0$, i.e., revenue sharing induces the dominant team (club 1) to decrease its investment. Since revenue sharing decreases competitive balance, ${ }^{18}$ the underdog (club 2) has to decrease its investment as well, i.e. $\frac{d x_{2}}{d \alpha}>0$.

(ib) If club 2 is the dominant team in equilibrium, i.e., $w_{2}>w_{1}$, then $\widehat{u}_{21}>0$ and thus the numerator $\widehat{u}_{21} \widehat{u}_{1 \alpha}-\widehat{u}_{11} \widehat{u}_{2 \alpha}$ of $\frac{d x_{2}}{d \alpha}$ is positive. It follows that that $\frac{d x_{2}}{d \alpha}>0$, i.e., revenue sharing induces the dominant team (club 2) to decrease its investment.

\footnotetext{
${ }^{18}$ See part (b) of Proposition 6.
} 
Since revenue sharing decreases competitive balance, the underdog (club 1) has to decrease its investment as well, i.e. $\frac{d x_{1}}{d \alpha}>0$.

(ii) Assume that $b>m_{1}+m_{2}$. In this case, $\widehat{u}_{1 \alpha}<0$ and $\widehat{u}_{2 \alpha}<0$.

(iia) If club 1 is the dominant team in equilibrium, i.e., $w_{1}>w_{2}$, then $\widehat{u}_{12}>0$ and thus the numerator $\widehat{u}_{12} \widehat{u}_{2 \alpha}-\widehat{u}_{22} \widehat{u}_{1 \alpha}$ of $\frac{d x_{1}}{d \alpha}$ is negative. It follows that $\frac{d x_{1}}{d \alpha}<0$, i.e., revenue sharing induces the dominant team (club 1) to increase its investment. Since revenue sharing increases competitive balance, ${ }^{19}$ the underdog (club 2) has to increase its investment as well, i.e. $\frac{d x_{2}}{d \alpha}<0$.

(iib) If club 2 is the dominant team in equilibrium, i.e., $w_{2}>w_{1}$, then $\widehat{u}_{21}>0$ and thus the numerator $\widehat{u}_{21} \widehat{u}_{1 \alpha}-\widehat{u}_{11} \widehat{u}_{2 \alpha}$ of $\frac{d x_{2}}{d \alpha}$ is negative. It follows that $\frac{d x_{2}}{d \alpha}<0$, i.e.,revenue sharing induces the dominant team (club 2) to increase its investment. Since revenue sharing increases competitive balance, the underdog (club 1) has to increase its investment as well, i.e. $\frac{d x_{1}}{d \alpha}<0$.

(iii) Assume that $b=m_{1}+m_{2}$. In this case, $\widehat{u}_{1 \alpha}=0$ and $\widehat{u}_{2 \alpha}=0$. It immediately follows that the numerator is zero and thus $\frac{d x_{1}}{d \alpha}=\frac{d x_{2}}{d \alpha}=0$. That is, revenue sharing has no effect on talent investments.

Part (b) Suppose that $b>m_{1}+m_{2}$. We claim that a higher degree of revenue sharing increases competitive balance if either the small-market club or the largemarket club is the dominant team in equilibrium. In the case that both clubs have equal playing strength in equilibrium, the IP holds.

We derive

$$
\frac{\partial \widehat{W R}^{*}}{\partial \alpha}=\frac{\left[b-\left(m_{1}+m_{2}\right)\right]\left[\left(m_{1}+\gamma_{1}\right)-\left(m_{2}+\gamma_{2}\right)\right]}{\left(\gamma_{2}+\alpha\left(m_{2}-b\right)-(1-\alpha) m_{1}+b\right)^{2}}
$$

The sign of $\frac{\partial \widehat{W R}^{*}}{\partial \alpha}$ only depends on $m_{1}+\gamma_{1} \lesseqgtr m_{2}+\gamma_{2}$. Note that

$$
\frac{\partial M R_{1}}{\partial \alpha}=\frac{x_{2}}{\left(x_{1}+x_{2}\right)^{2}}\left(m_{1}+m_{2}-b\right)<0 \text { and } \frac{\partial M R_{2}}{\partial \alpha}=\frac{x_{1}}{\left(x_{1}+x_{2}\right)^{2}}\left(m_{1}+m_{2}-b\right)<0 .
$$

It follows that a higher degree of revenue sharing (i.e., a lower parameter $\alpha$ ) implies higher marginal revenue for both clubs.

We differentiate three cases:

(i) Assume that $m_{1}+\gamma_{1}=m_{2}+\gamma_{2}$. In this case, it is easy to see that revenue sharing has no effect on competitive balance and the IP holds, since $\frac{\partial \widehat{W R}^{*}}{\partial \alpha}=0$.

(ii) Assume that $m_{1}+\gamma_{1}>m_{2}+\gamma_{2}$. In this case, the large-market club 1 invests more in talent and thus has a higher win percentage than the small-market club 2 in equilibrium. Furthermore, $\left|\frac{\partial M R_{1}}{\partial \alpha}\right|<\left|\frac{\partial M R_{2}}{\partial \alpha}\right|$ since $x_{1}>x_{2}$, such that the positive

\footnotetext{
${ }^{19}$ See part (b) of Proposition 5 .
} 
effect of revenue sharing on marginal revenue is stronger for the small-market club. Therefore, $\widehat{W R}^{*}>1$ decreases and competitive balance increases if revenue sharing increases.

(iii) Assume that $m_{1}+\gamma_{1}<m_{2}+\gamma_{2}$. In this case, the small-market club 2 invests more in talent and thus has a higher win percentage than the large-market club 1 in equilibrium. Furthermore, $\left|\frac{\partial M R_{2}}{\partial \alpha}\right|<\left|\frac{\partial M R_{1}}{\partial \alpha}\right|$ since $x_{2}>x_{1}$, such that the positive effect of revenue sharing on marginal revenue is stronger for the large-market club. Therefore, $\widehat{W R}^{*}<1$ increases and competitive balance increases if revenue sharing increases.

This completes the proof of the proposition.

\section{A.5 Proof of Proposition 6}

Part (a) Note that we have proven the claim already in Proposition 5.

Part (b) Suppose that $b<m_{1}+m_{2}$. We claim that a higher degree of revenue sharing decreases competitive balance if either the small-market club or the largemarket club is the dominant team in equilibrium. In the case that both clubs have equal playing strength in equilibrium, the IP holds.

As in the proof of Proposition 5, the sign of $\frac{\partial \widehat{W R}^{*}}{\partial \alpha}$ only depends on $m_{1}+\gamma_{1} \lesseqgtr$ $m_{2}+\gamma_{2}$. Note that $\frac{\partial M R_{1}}{\partial \alpha}>0$ and $\frac{\partial M R_{2}}{\partial \alpha}>0$ if $b<m_{1}+m_{2}$. It follows that a higher degree of revenue sharing (i.e., a lower parameter $\alpha$ ) implies higher marginal revenue for both clubs.

Again, we differentiate three cases:

(i) Assume that $m_{1}+\gamma_{1}=m_{2}+\gamma_{2}$. In this case, it is easy to see that revenue sharing has no effect on competitive balance and the IP holds, since $\frac{\partial \widehat{W R}^{*}}{\partial \alpha}=0$.

(ii) Assume that $m_{1}+\gamma_{1}>m_{2}+\gamma_{2}$. In this case, the large-market club 1 invests more in talent and thus has a higher win percentage than the small-market club 2 in equilibrium. Furthermore, $\frac{\partial M R_{1}}{\partial \alpha}<\frac{\partial M R_{2}}{\partial \alpha}$ since $x_{1}>x_{2}$, such that the negative effect of revenue sharing on marginal revenue is stronger for the smallmarket club. Therefore, $\widehat{W R}^{*}>1$ increases even more and competitive balance decreases if revenue sharing increases.

(iii) Assume that $m_{1}+\gamma_{1}<m_{2}+\gamma_{2}$. In this case, the small-market club 2 invests more in talent and thus has a higher win percentage than the large-market club 1 in equilibrium. Furthermore, $\frac{\partial M R_{2}}{\partial \alpha}<\frac{\partial M R_{1}}{\partial \alpha}$ since $x_{2}>x_{1}$, such that the negative effect of revenue sharing on marginal revenue is stronger for the largemarket club. Therefore, $\widehat{W R}^{*}<1$ decreases even more and competitive balance decreases if revenue sharing increases.

This completes the proof of the proposition. 


\section{References}

Atkinson, S., Stanley, L. and Tschirhart, J. (1988), 'Revenue Sharing as an Incentive in an Agency Problem: An Example from the National Football League', RAND Journal of Economics 19, 27-43.

Clark, D. and Riis, C. (1998), 'Contest Success Functions: An Extension', Economic Theory 11, 201-204.

Cyrenne, P. (2009), 'Modelling Professional Sports Leagues: An Industrial Organization Approach', Review of Industrial Organization 34, 193-215.

Dietl, H., Franck, E. and Lang, M. (2008), 'Overinvestment In Team Sports Leagues: A Contest Theory Model', Scottish Journal of Political Economy 55(3), 353368.

Dietl, H. and Lang, M. (2008), 'The Effect of Gate Revenue-Sharing on Social Welfare', Contemporary Economic Policy 26, 448-459.

Dietl, H., Lang, M. and Werner, S. (2009), 'Social Welfare in Sports Leagues with Profit-Maximizing and/or Win-Maximizing Clubs', Southern Economic Journal 76(2), 375-396.

Dixit, A. (1986), 'Comparative Statics for Oligopoly', International Economic Review 27, 107-122.

Dixit, A. (1987), 'Strategic Behavior in Contests', American Economic Review $77,891-898$.

Eckard, E. (2006), 'Comment: "Professional Team Sports Are Only a Game: The Walrasian Fixed-Supply Conjecture Model, Contest-Nash Equilibrium, and the Invariance Principle"', Journal of Sports Economics 7(2), 234-239.

El-Hodiri, M. and Quirk, J. (1971), 'An Economic Model of a Professional Sports League', Journal of Political Economy 79, 1302-1319.

Falconieri, S., Palomino, F. and Sákovics, J. (2004), 'Collective versus Individual Sale of Television Rights in League Sports', Journal of the European Economic Association 5, 833-862.

Fort, R. (2005), 'The Golden Anniversary of 'The Baseball Players Labor Market", Journal of Sports Economics 6, 347-358. 
Fort, R. and Quirk, J. (1995), 'Cross-Subsidization, Incentives, and Outcomes in Professional Team Sports Leagues', Journal of Economic Literature 33, 12651299.

Fort, R. and Quirk, J. (2004), 'Owner Objectives and Competitive Balance', Journal of Sports Economics 5, 20-32.

Fort, R. and Quirk, J. (2007), 'Rational Expectations and Pro Sports Leagues', Scottish Journal of Political Economy 54, 374-387.

Fort, R. and Winfree, J. (2009), 'Sports Really Are Different: The Contest Success Function, Marginal Product, and Marginal Revenue in Pro Sports Leagues', Review of Industrial Organization 34, 69-80.

Garcia-del Barrio, P. and Szymanski, S. (2009), 'Goal! Profit maximization and win maximization in football leagues', Review of Industrial Organization 34, 45-68.

Grossmann, M. and Dietl, H. (2009), 'Investment Behaviour in a Two Period Contest Model', Journal of Institutional and Theoretical Economics 165(3), 401417.

Grossmann, M., Dietl, H. and Lang, M. (2009), 'Revenue Sharing and Competitive Balance in a Dynamic Contest Model', Review of Industrial Organization (forthcoming).

Grossmann, M., Dietl, H. and Trinkner, U. (2008), 'The Effect of Marginal Cost Elasticity on Competitive Balance', Journal of Sports Economics 9(4), 339.

Hirshleifer, J. (1989), 'Conflict and Rent-Seeking Success Functions: Ratio vs. Difference Models of Relative Success', Public Choice 63, 101-112.

Hoehn, T. and Szymanski, S. (1999), 'The Americanization of European football', Economic Policy 14, 204-240.

Késenne, S. (2000), 'Revenue Sharing and Competitive Balance in Professional Team Sports', Journal of Sports Economics 1, 56-65.

Késenne, S. (2005), 'Revenue Sharing and Competitive Balance - Does the Invariance Proposition Hold?', Journal of Sports Economics 6, 98-106.

Késenne, S. (2006), 'The Win Maximization Model Reconsidered: Flexible Talent Supply and Efficiency Wages', Journal of Sports Economics 7, 416-427.

Késenne, S. (2007), The Economic Theory of Professional Team Sports - An Analytical Treatment, Edward Elgar, Cheltenham, UK. 
Lazear, E. and Rosen, S. (1981), 'Rank-Order Tournaments as Optimum Labor Contracts', Journal of Political Economy 89, 841-864.

Rascher, D. (1997), A model of a professional sports league, in W. Hendricks, ed., 'Advances in Economics of Sport', Vol. 2, JAI Press, Greenwich, pp. 27-76.

Rottenberg, S. (1956), 'The Baseball Players' Labor Market', Journal of Political Economy 64, 242-258.

Skaperdas, S. (1996), 'Contest Success Functions', Economic Theory 7, 283-290.

Szymanski, S. (2003), 'The Economic Design of Sporting Contests', Journal of Economic Literature 41, 1137-1187.

Szymanski, S. (2004), 'Professional Team Sports are Only a Game: The Walrasian Fixed Supply Conjecture Model, Contest-Nash Equilibrium and the Invariance Principle', Journal of Sports Economics 5, 111-126.

Szymanski, S. and Késenne, S. (2004), 'Competitive Balance and Gate Revenue Sharing in Team Sports', Journal of Industrial Economics 52, 165-177.

Tullock, G. (1980), Efficient Rent-Seeking, in J. Buchanan, R. Tollison and G. Tullock, eds, 'Toward a Theory of the Rent Seeking Society', University Press, Texas, pp. 97-112.

Vrooman, J. (1995), 'A General Theory of Professional Sports Leagues', Southern Economic Journal 61, 971-990.

Vrooman, J. (2007), 'Theory of the Beautiful Game: The Unification of European Football', Scottish Journal of Political Economy 54, 314-354.

Vrooman, J. (2008), 'Theory of the Perfect Game: Competitive Balance in Monopoly Sports Leagues', Review of Industrial Organization 31, 1-30.

Zimbalist, A. (2003), 'Sport As Business', Oxford Review of Economic Policy 19, 503-511. 